\title{
On Incompatible Aspects in the Style of Japanese Design: referring to a New Development in Phenomenology
}

The style of Japanese design is often said to contain two incompatible aspects: a traditional affective style, and a contemporary style consisting of a highly technological or mechanical appearance and a popular "kawaii" appearance. On the one hand, the maintenance of a classical style inherited from traditional Japanese arts (e. g. Kagura, Noh, tea ceremony), religion (e. g. Shinto or Buddhism), and classic literature (e. g. The Tale of Genji ) may be identified in Japanese design. On the other hand, the sophisticated "beautility" realized in Japanese industrial products and the "kawaii" look of Pokemon monsters have become icons of modern Japanese culture. Often introduced as an example of a contemporary Japanese artist, Murakami Takashi depicts many "animelooking" characters while emphasizing their "flatness," an element considered central to Japanese traditional paintings. In fact, he actually studied Japanese-style paintings at the prestigious Tokyo University of the Arts. This coexistence between the two supposedly incompatible aspects made Murakami's art famous. In this manner, the two aspects coexist within actual artworks and produce their unique value; however, how this coexistence is possible has yet to be examined theoretically. By examining classical Japanese artworks and poems, we will attempt to show that the incompatible aspects really have a single origin, for which a new development of phenomenology constructed by Gernot Böhme and his concept of "Atmosphäre" will be able to provide an account for.

keywords japanese design, shareable attitude, patternization, affectiveness, phenomenology

\section{Introduction}

In Japanese design, representations of nature are adapted as one of several frequently employed motifs. For example, red leaves (momiji) on flowing water, or red leaves with a deer. We can easily find these variations applied both in artworks and everyday products. The first example is a famous Japanese painting by Yokoyama Taikan in the early zoth century (Fig.1). Taikan was a pupil of Professor Okakura Tenshin at the Tokyo Art School (the precursor of Tokyo University of the Arts). In this painting, he represented the autumnal landscape with deep red leaves on clear blue water. The next example is Hanafuda (flower cards), invented for a picture matching game modelled after Western playing cards, which came from Portugal at the end of the 16th century (Fig.2). Each of the twelve months in a year has four cards depicting a set of typical objects for that month, making 48 cards in total. Although it is said the number of cards reveals its origin from Western playing cards, Hanafuda additionally reflects seasonal change. In the cards for October, the same motif of red leaves is represented. In these two cases, "verisimilitude" is not the criterion for the quality marking a difference between artworks and everyday products. Of course, there was and is a distinction between fine artistic expressions and banal ones in Japan. The problem is what kind of elements prevail in these Japanese designs. 
theme 1

theory

Figure 1.

Yokoyama Taikan

(1931), Red Leaves.

Figure 2.

An example of Hanafuda (one of cards for October) strand 3

aesthetics beyond style
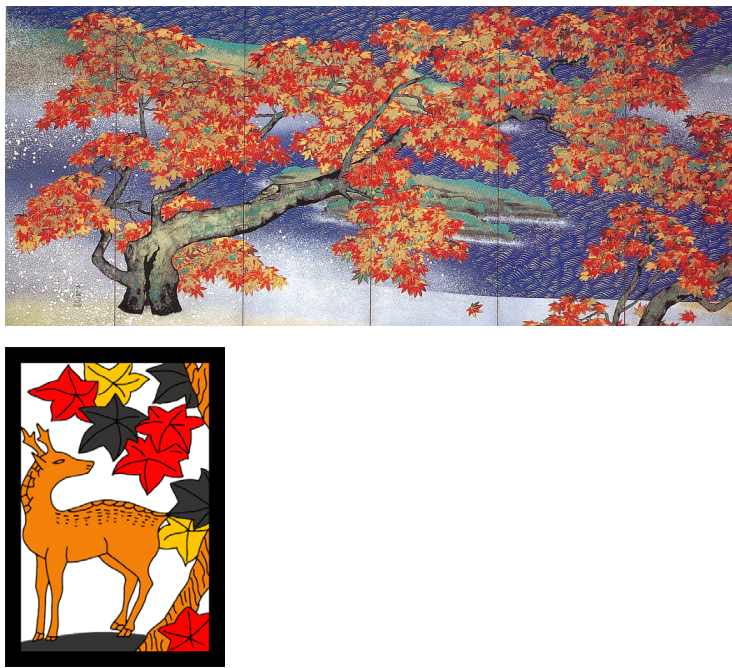

1. What is Japanese Design?

The designs such as "red leaves on flowing water" and "red leaves with a deer" remind those who belong to the Japanese cultural sphere of certain works of Japanese classic literature. Here is an example of a waka poem written in the gth century Heian era: Oku-yama ni / momiji fumi-wake / naku shika no / kowe kiku toki zo / aki ha kanashiki (by Senior Assistant Minister Sarumaru). It has been translated as: "when I hear the voice of the stag crying for his mate stepping through the fallen leaves deep in the mountains - then is the time that autumn is saddest" (Mostow c.1996: 155). As these images are common in the Japanese cultural sphere's imaginary, most Japanese people can quickly visualizes such scenes indicated by this waka, even though most people do not know its author, nor know how stags cry. Some particular scenes are shared among people because of "media effects". Television, magazines, and travel brochures reproduce the scenes which have been represented traditionally in poems and paintings in Japan. Donald Keene, an American translator of Japanese literature, wrote in 1968: "( $\mathrm{t}$ )he cult of cherry blossoms, which apparently originated at the court in Kyoto, today is universal: radio announcements inform the breathless public at which sites the blossoms are eight-tenths opened and at which seven-tenths, and eager busloads of factory workers head for the suitable spots" (Keene 1969: 294). Today, they may take pictures and post them on their blog with additional comments about how they felt then. This in turn makes the readers accustomed to the scenes accompanied by particular emotions. It is this circulation of emotional scenes that provide them with strong appeal. A lot of Ukiyoe prints based on typical seasonal scenes, such as sites famous for their plum blossoms, irises or silver grass, promoted tourism to go see such places. These prints attest that this circulation of emotional scenes has been common in Japan.

Consequently, representations of nature in Japanese design have begun to function not as simply ornamental, but as signals for evoking particular emotions. In the Japanese upper class, some furnishing wears are replaced depending on (or in anticipation of) the seasons. A screen or dishes with designs of red leaves should be put away before winter arrives, thereby preparing the attitude -- both mental and physical -- towards the coming season, as well as evoking the feeling of seasonal change. Looking at the design of red leaves 
before the autumn rolls around reminds them of their personal experience in previous autumns and prompts them to associate it with particular emotions expressed in famous poems or paintings. In short, it induces them to extract themselves from their status quo and to immerse themselves into an attitude evoked by the design beyond the distance in space and time.

Haiku is another form of Japanese classic poetry. In contrast with waka, which often contains an author's emotional effusion because of its higher syllable count, most haiku are composed of single descriptions of a scene without any space for narrative or manifestation of sentiment in the poem itself. This makes haiku become a mere description for evoking in readers a common attitude toward the depicted scene. Focused on sharing the same attitude, there is no need for detailed depictions of the scene or the author's feeling, which would make a haiku too personalized for readers to share the attitude. According to Keene, "(s)uggestion depends on a willingness to admit that meanings exist beyond what can be seen or described... (F)or the Japanese poet or connoisseur of art the pleasures of suggestion could become an end in themselves to the exclusion of considerations of convincing representation" (Keene 1969: 298). In this sense, much of Japanese expression depicts falling cherry blossoms over those in full bloom, and a snow scene from behind a shöji screen made of semi-transparent paper, rather than the scene shown overtly. It is important not to experience an event at its spatial/temporal acme directly, but to be aware of it by suggestion.

Seasonal scenes epitomized by typical natural objects have produced many forms of artistic expression which circulated through the public sphere evoking shareable attitudes. On the one hand, this circulation tends to reduce the expression into cliché rapidly. Shown here are parts of Japanese folding screens from the Edo era made by Japanese designer, Ogata Korin and its application to contemporary everyday design named "Korin's waves" and "Korin's pine trees" (Fig.3). Although the former still portrays a fresh attitude that people would experience in front of pine trees on the rocks standing against strong waves, the latter's does not maintain the original feeling of the sublime. Therefore, it seems to be important for Japanese artists: to be sensitive to attitudes many people have experience with but which no one has articulated into an individual artistic expression; to examine what kind of components construct this shared attitude; to compose these components into an artistic expression eliminating details that would be too personal to inhibit people from communing with it. Just as our life undergoes changes according to changes of the times, new attitudes should emerge with new expressions for shared connections. Contemporary haiku poems contain new technological products such as a mobile phone or jet lag as their subject, just as in famous haiku-like poetry by Ezra Pound, depicting the platform of the underground:

The apparition of these faces in the crowd: Petals, on a wet, black bough. (Pound 1914: 467)

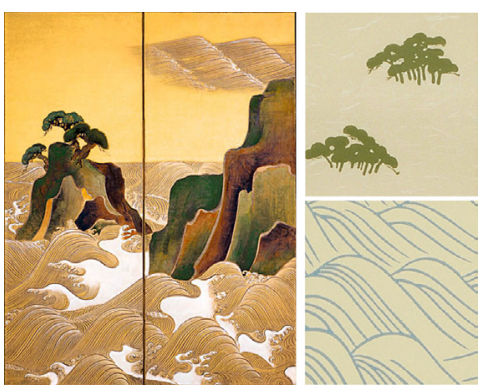

Figure 3 . Left: Ogata Korin (18c), Waves at Matsushima (details). Right: Contemporary designs inspired by the Korin's painting. 


\section{Phenomenological Analysis}

How can we theoretically analyse the shareable attitude as we have described? It would be difficult by simply translating Japanese ideas verbatim into other languages. So, we will refer to some words Western writers or scholars used when they encountered Japanese culture. For example, English poet Ezra Pound wrote about the features of Japanese haiku in his essay "Vorticism":

In a poem of this sort, one is trying to record the precise instant when a thing outward and objective transforms itself, or darts into a thing inward and subjective. (Pound 1914: 467)

As Pound remarked, we could say that patternized elements of Japanese design are signals evoking subjective emotion as well as objective representations of a scene. But, if we analyse them in this way, we still remain in modern Western thinking which keeps clear distinctions between subject and object. Rather, we should express it as follows: Japanese design leads people to experience an entity which is at once subjective and objective. German phenomenologists Gernot Böhme, author of Atmosphere: Essays on New Aesthetics, criticizes modern Western aesthetics:

Nature has always been in some ways a theme in modern aesthetics as well as in art. As for aesthetic theory, however, it has never been a theory of nature, but rather always been that of the subject... Kant's aesthetics is certainly subjective throughout, insofar as the judgement of beauty and sublime is founded on an inner state. (Böhme 2013: 225)

"Atmosphere" is what Böhme proposed to indicate a primitive perception preceding a clear distinction between subject and object, in order to elevate natural beauty and design previously relegated to a lower level by modern aesthetics that developed as a theory of the subject's judgement on an object and has "naturally always oriented itself to the noble, true, great art" (Böhme 2001: 17). According to him:

Perception is feelings of an experience that I am here, and of how and where I find myself. Specific sensory perceptions can gradually differentiate from these feelings and finally so do an ego-pole and an object of perception. What is felt, is primarily something atmospheric. It is not differentiated as such according to sensory qualities, but can be specified according to the senses. In contrast, it always has, as we may say, an affective tone, i.e. is threatening, exhilarating, depressing, alluring, etc. (Böhme 2001: 42)

Here, we think it telling that Böhme takes a haiku of Matsuo Bashô as an example of this "atmosphere" (Böhme 2013: 66). If, as Böhme says, this atmospheric precedes a "differentiation into specific sensory perceptions", it is natural to think that it has a synesthetic character: "Here again, we will take synaesthesia to determine it as a character of atmosphere" (Böhme 2013: 87). In this sense, it is illustrative that Russian film maker Sergei Eisenstein, who attended a performance of Kabuki theatre in Leningrad in 1928, already remarked on its synesthetic expression:

Here a single monistic sensation of theatrical "provocation" takes place. The Japanese regards each theatrical element, not as an incommensurable unit among the various categories of affect (on the various sense-organs), but as a single unit of theater. (Eisenstein 1928: 21) 
This synesthetic character of Kabuki theatre derives from Japanese aesthetics which does not allow any personage to be a real existence but a patternized character. Though not specially discussing Japanese theatre, Böhme explains, "(t)he theatre is a world of appearances" (Böhme 2001: 117), where sight and sound are not undertaken by a particular personage with specified sensory perceptions as his/her personal experience, but rather they are synthetically expressed and shared among those who are on the stage and in the auditorium.

Here, we can conclude that what Böhme calls "atmosphere" is almost what Japanese design realizes in its products. If those who are accustomed with them could remark an insufficiency in Böhme's explanation, it is that he misesteems their nostalgic quality. Every experience of atmosphere takes on such a quality because sharing an atmosphere that is an extract from particular subjects and objects always accompanies a feeling as if it were a repetition of a past experience of it. However joyous or painful one feels in ordinary life as well as in response to a work, someone within the Japanese cultural sphere is apt to think it is a recurrence of what someone once felt and expressed in a particular poem or design. We should not assert that they are influenced by the Buddhist thinking of "all is vanity", but we can still say that it is as if many Japanese live their lives "theatrically" or aesthetically.

\section{Conclusion}

Our discussion began with an awareness that Japanese design contains "two incompatible aspects", but it is possible to compound these aspects through the intermediary of the idea of "atmosphere" suggested by Böhme. Expressing "atmosphere" which became a shareable attitude (or, to use Böhme's terminology, "disposition") in Japanese culture by the help of media effects, Japanese design shows on the one hand "patternization" that eliminates verisimilar details in the aspect of production, and on the other hand "affectiveness" that expresses the emotions associated with these patterns in the aspect of reception. As a result, Japanese design takes on a synecdochical quality. In fact, Anime or Manga characters are differentiated from each other by their patternized factors such as hairstyle and its colour. These factors, however, suggest a certain temperament or behavior, in short "atmosphere". For example, pink coloured hair often accompanies a girly character. Japanese modern industrial products as well, which appear simplified in accordance to the principles of beautility, have the potential -- insofar as they are familiar enough to become a component of a particular time/place's everyday "atmosphere" -- of being added to a larger design or participating in an appropriate design for that atmosphere.

\section{References}

Böhme, G. (2001) Aisthetik: Vorlesungen über Ästhetik als allgemeine Wahrnehmungslehre, München: Wilhelm Fink Verlag (citations are translated by presenters). Böhme, G. (2013) Atmosphäre: Essays zur neuen Ästhetik, Berlin: Suhrkamp Verlag (citations are translated by presenters).

Eisenstein S. (1949), Film Form: Essays in Film Theory, trans. by Jay Leida, Harcourt: Brace and World Inc.

Keene, D. (1969) 'Japanese aesthetics', in Philosophy East and West, vol.XIX, no.3, July, pp.293-306. Mostow, J. (c1996) Pictures of the Heart: The Hyakunin Isshu in Word and Image, Honolulu: University of Hawaii Press.

Pound, E. (1914) 'Vorticism', in Fortnightly Review, no.96, September, pp.461- 471. Suan, S. (2013) The Anime Paradox: Patterns and Practices through the Lens of Traditional Japanese Theater, Leiden/Boston: Grobal Oriental. 
